\title{
Policy Orientation in Inclusive Education in the Republic of Cameroon: Problems and Perspectives
}

\author{
Dr. Titanji Peter Fon \\ Vice Dean in charge of Programmes and Academic Affairs, \\ Faculty of Education, University of Buea, Cameroon \\ Email: titanji@yahoo.com
}

\section{Doi:10.5901/jesr.2016.v6n3p113}

\begin{abstract}
In this paper the literature on the unique characteristics of educational organizations and themes emerging from educational reform efforts are used to inform policy orientations and practices aimed at achieving the goal of greater inclusion within the Cameroon education sector. It is argued that the goal of inclusion will be achieved, if among other things, policies and practices are not dominated by the rational model of viewing educational organizations. A multi-frame perspective is recommended. It is also argued that attempts to create and nurture more inclusive educational environments will need to be based on holistic policy and practice perspective. For example, it will require efforts to strengthen relationships between family members, re-visiting the use of tests and examinations, how time is used, and drawing a fine line between education and schooling.
\end{abstract}

Keywords: Republic of Cameroon, inclusive education, policies, perspectives.

\section{Introduction}

Policy makers and other practitioners face and will continue to face many problems and dilemmas in conversations on inclusion. The concept of inclusion is very controversial and consequently has had many definitions (Armstrong, Armstrong \& Spandagou, 2011; Graham \& Slee, 2008; Fuchs \& Fuchs, 1994). The lack of a shared meaning of inclusion acts as a barrier to the provision of quality education to all learners. Inclusive education is concerned with the removal of all barriers to learning from the perspectives of access, experiences, and outcomes. In this paper the concept of inclusion is simply defined as equality of opportunity of access and experiences to quality education regardless of personal background variables of learners. This paper, organized into three main parts, seeks to provide, expand, and enrich the ideas and approaches that can be used to address issues of inclusion. More specifically, the main objective of the paper is to shed light on the unique characteristics of educational organizations in order to inform policy makers and practitioners of some of the critical considerations that have often been neglected during efforts to make Cameroon's education sector more inclusive. The first part presents arguments why all education stakeholders must work towards greater inclusion. In the second part of the paper, the unique characteristics of educational organizations are presented. This is because of my strong belief that the goal of inclusion cannot be achieved, albeit at optimal levels, without a mastery of how educational organizations work in reality rather than what text books tell us. One of the ways forward is to use these characteristic to anchor policies and practices. The third part of the paper is devoted to what I think we need to do if inclusion if going to be a sustained reality. It addresses some of the things we have tended to neglect. It is argued that we need to pay more attention to the contributions of families and communities, distinguish between education and schooling because this has profound implications for inclusion, re-visit common pedagogical practices in schools, and treat students as human beings in order to strengthen their bonding with schools, among other things.

The researcher adopted a simple methodology - a review of literature deemed relevant to the objectives and its implications. Literature was reviewed in the area of organizational theory in general and specifically that which can enable us to better understand the unique characteristics of educational organizations, including but not limited to structural, human resource, political, and symbolic frames or lenses for understanding and guiding the functioning of the education sector in desired directions. In addition, this article is based on a review of literature that brings out some of the often neglected variables that often get neglected but are critical to the success of policies and practices of inclusion. It is argued that efforts to create and sustain more inclusive teaching and learning environments must be based on a mastery of how educational organizations function as opposed to how they are assumed to function according to rational 
structural theories.

\section{Arguments for Inclusion}

There are many reasons why inclusion should be a front-burner issue within the context of Cameroon and other parts of the world. Some of the arguments are economic, socio-cultural, and political. In addition, inclusion is a rights issue. Policies aimed at greater inclusion should adopt a comprehensive approach rather than dominantly pursuing school improvement efforts. Focusing on schools alone is like trying to pay more attention to curing an ailment while ignoring prevention. One of the essential things that need to be done is to increase commitment to prevent difficulties in the lives of all children and their families. Not doing this will require a more expensive strategy: counteracting the effects of poverty and other burdens after the damage has been done (Howe II, 1993; p. 31).

When a critical mass of Cameroonians feel excluded they may be devoid of hope of a better future within an increasingly knowledge-driven environments. In other words, their contributions to sustainable nation building are likely to be way short of expectations. The education of every Cameroon constitutes investment in social capital, from a functionalist perspective. The possibility of greater consequences (social, economic, political etc.) resulting from perceptions of alienation and discouragement constitutes a very powerful argument to pay attention to greater inclusion. Excluded persons can cause social problems with the potential to affect every one of us.

In addition is a social capital argument. One of the goals of this country is to promote national unity and integration using education as part strategy. Social capital is a concept derived from the work of James Coleman entitled Equality of Educational Opportunity (1966). It comprises, as summarized by Howe II "the mixture of human relationships and opportunities on which children and youth depend for successful growth to maturity." (p. 33). Many young persons are excluded from quality education at various levels of schooling because of the erosion of social capital. Coleman (1966) explains the meaning of social capital as follows:

What I mean by social capital in the raising of children is the norms, the social networks, and the relationship between adults and children that are of value for the child's growing up....Altogether, the social capital in family and neighborhood available for raising children has declined precipitously. The cost will, of course be borne by the next generation, and borne disproportionately by the disadvantaged of the next generation.

Social capital has been eroded because of changes within the larger society, among them: increasing number of women who have joined the paid labour force, higher divorce rates, many more single-parent families, and much more time family members watch TV rather than talking with each other. The implications of these changes mean that many children spend less time with their parents and consequently less attention and intimacy. Should many more Cameroonians be included in the education sector, we will be definitely building social capital that will serve the achievement of this country's mission as contained in its Growth and Employment Strategy Paper (2010-2020). In other words, this country's ability to achieve its development agenda is significantly tied to deliberate efforts to provide quality education to all.

We need to minimize the number of Cameroonians who feel excluded in the education sector. Failure to do so may lead to the creation of many more Cameroonians without hope of a better future, individuals filled with rage whose consequences are difficult to predict in their entirety. If we do not strive towards greater inclusion, we will bear the cost sooner or later and in various forms, among them: the lack of readiness of significant numbers of children to benefit from schooling, in the form of increased failure in tests and examinations; graduates from schools who cannot contribute optimally to the productive sector, greater incidence of disruptive behaviour, greater incidence of preventable diseases such as HIVIAIDs, among others. The social costs of dealing with these consequences may outweigh costs associated with ensuring greater inclusion.

Finally, inclusion is a moral and human rights issue. The UN Charter identifies access to education, at least at the basic level, a right of all children. This features prominently in the 1996 Constitution of this country and other legal instruments. For a long time in the life of this country a greater sense of community rather than individualism was a shared norm that held us together. To foster inclusion requires the adoption of policies and encourage practices that reinforce norms of community.

\section{Understanding Educational Organizations}

What are the characteristics of educational organizations? If we render a simple answer to this question, we will be unable to create and sustain inclusive education policies and practices. The reality in the world of policies and practices 
is that this question has been dominantly answered using single frame thinking. Thinking about organizations in general and educational organizations in particular has a long history and diverse perspectives have been used. These perspectives are variously called maps, frames, images, and metaphors. In this paper I have decided to use the label of frames. A frame according to Bolman and Deal (1991) is an image of an organization that can be used by practitioners to put some order to their experiences and determine appropriate actions in given situations (in this case inclusion). Administrators, leaders, policy makers and other members of the "education community" (Cameroon, 98/004) have their own frames of educational organizations. Frames have many advantages, among them enabling us to determine what type of information to collect in given situations in order to inform our actions. In addition to being used as lenses through which to see things, frames are tools for needed actions.

Advocates for inclusion (for example, policy makers, non-governmental and civil society organizations, educators etc.) must possess a mastery of how educational organizations work in reality as opposed to how they are supposed to work. One of the ways of knowing how they actually work is to view and understand educational organizations using different lenses or frames. In their book entitled Reframing Organizations: Artistry, Choice, and Leadership Bolman and Deal (1991) identify and examine four frames (structural, political, symbolic and human resource) that need to be used to understand the unique characteristics of educational organizations. I have briefly stated the main substance of each of these frames as well as their implications for those seeking to ensure that schools are more inclusive teaching and learning environments for all as a prerequisite for sustainable development and the achievement of the mission assigned to the education sector in the Republic of Cameroon's Growth and Employment Strategy Papers (2010-2020) or what is commonly referred to as Vision 2025. The main ideas of these frames have been distilled from Bolman and Deal (1991) and used to shed light on inclusion.

\section{The Structural or Rational Frame}

Educational organizations have been dominantly assumed, albeit wrongly, to be rational organizations. A rational organization according to Patterson et al., (1986) is one which, among other things, assumes that the goals of education are clearly stated by persons occupying high positions within the hierarchical structural arrangement and shared by the various stakeholders. It further assumes that power, the ability to influence others and get things done, is located in formal positions or offices, and that there is a one best way of doing things which needs to be identified and standardized. The rational frame also assumes that the external environment of educational organizations is quite stable and can always be predicted. The rational or structural frame of organizations lays greater emphasis on formal roles and relationships. The structure of an educational organization is commonly reflected in its organizational chart. Structures are not haphazardly created but in ways that align with the business of an organization, its environment and way of doing things (technology). Educational organizations are structured partly based on the structure of bureaucracy which requires the allocation of different responsibilities or tasks to the various workers or groups while creating rules and administrative hierarchies for coordination and control of the diverse activities which are interrelated.

To Patterson et al., (1986) the rational model fails to capture the reality of educational organizations. In their opinion, reality is better captured by what they describe as the "non-rational" model which assumes that educational organizations are characterized by stakeholders with interests which sometimes conflict; the ability to influence others does not only lie in an official position because of the existence of informal leaders; that the external environment is not always predictable and decisions sometimes made serve the interests of members (depending on their bargaining power) rather than the interests of schools as organizations.

\subsection{Human Resource Frame}

Social scientists, mostly psychologists who have studied organizations, can be credited with laying the foundation of the human resource frame. Its main premise is that educational organizations are partly made up of human beings with diverse needs, feelings and prejudices. For example, within educational organizations are administrators, teachers, students, non-academic personnel, among other stakeholders especially those within the external environment. Teachers and other functionaries have certain competencies (knowledge, skills and professional dispositions) and lack others that are critical to effectiveness in performing assigned responsibilities. Workers within organizations have the capacity to acquire new capacities as they work in dynamic or changing environments. On the other hand, they also have great capacity to maintain things the way they are or to be conservative. Based on these ideas, a regular challenge is to ensure the continuous professional development of workers and structures to enable them satisfy their needs. 
The relationship between educational organizations and their human resources is a very functional one (Bolman and Deal, 1991). Consequently, it is critical to understand human nature in the process of creating and nurturing inclusive educational environments. Policy makers are likely to have certain assumptions about human beings. These assumptions may hurt (for example, engender resistance and hostility) or help (for example, ensure greater commitment and high levels of motivation from personnel and other collaborators) the process of working towards greater inclusion. The implication here is that policy makers have the power to create and sustain enabling interpersonal relationships critical to inclusion or do the reverse. In addition it is also argued that policy makers need to pay attention to basic issues such as participatory decision making processes and addressing other needs of educators as adults.

Policy makers in education have many challenges and one of them is to make the implementation of inclusion more meaningful, interesting to education personnel and other stakeholders. For example, if teachers do not possess the profiles to have high levels of efficacy beliefs relative to what they are expected to do, policies on inclusion are unlikely to succeed. There are many things that can be done to increase levels of commitment and motivation for inclusion, among them the provision of capacity building opportunities to ensure readiness.

One of the implications that emerge from the human resource frame is that pre-service and continuing professional development opportunities will have to be offered to ensure that practitioners do not doubt their own sense of efficacy. Training will require them to view old problems using new approaches and attack the problem of inclusion with more powerful tools (political, symbolic etc.). Without adequate training many educators will deal with issues of inclusion the hard way, making mistakes along the way. These mistakes are likely to have profound consequences for the distribution of quality education to all. From the perspective of those who work in organizations, the experiences of many fall far short of expectations. Work within some educational organizations have been described as being characterized by very little and no meaning than the value of a salary. This should shock us to collectively reflect on what needs to be done to make the process of educating future generations of Cameroonians more rewarding to individual educators and the larger society. If this is not done, there is great danger than inclusion will be limited to rhetoric.

\subsection{The Political Frame}

Educational organizations are political. This is because they are characterized by concepts such as scarcity of resources, diversity of stakeholders with sometimes conflicting expectations, bargaining and negotiation, the formation of coalitions, power fights, among others. The political frame emerges from the discipline of political science. Political scientists will view educational organizations as arenas with different stakeholders, each seeking to satisfy its own agenda or interests within a context of power plays and scarce resources. Consequently, there is bound to be conflict because of differences in aims or needs and the characteristics of the various stakeholders. Against this backdrop, concepts such as conflict, bargaining, negotiation and compromise, are bound to be very common. If they are not, something is definitely very wrong. Because working as individuals may not serve their needs, coalitions are often formed by members with shared interests as issues are addressed and new ones emerge.

According to Bolman and Deal (1991: xvi) educational organizations are "arenas that house political contests and political actors in their own right." A critical challenge for stakeholders interested in creating, nurturing and sustaining more inclusive educational environments is to diagnose the political realities of educational organizations and their environments as a prerequisite to set inclusion agendas and strategies to pursue them successfully. Educational organizations must be viewed as playgrounds within which the various actors of inclusion are enabled to express their interests.

The political frame points to the need for openness to a diversity of interests, the formation of alliances and adoption of lobbying strategies to better pursue interests that sometimes conflict. For example, operating using the political frame stakeholders will not be content to simply adopt policies on inclusion and expect that all else (acceptance, implementation, and continuation of inclusive practices) will logically follow. This is a rational approach that does not reflect the reality of educational organizations. If education stakeholders often have their own interests, this means that alliances will have to be formed as they fight to pursue them. Sometimes they will have to bargain and end up compromising their positions. In other words, what this means for efforts to adopt and implement policies on inclusion is that the process is not an easy, linear one but one which can sometimes be very messy. With many stakeholders involved, they must accept diversity of interests, scarcity of resources, negotiation and compromise, bargaining and lobbying as part of the game. For example traditionally advantaged groups are not likely to easily genuinely accept policies on inclusion for fear that their dominance will be threatened. Traditionally neglected groups will have to come together to pursue common interests without which much may not be accomplished. The implication here is that 
advocates of inclusion require broad and deep mastery of the competencies of a politician, not necessarily from a partisan perspective.

\subsection{The Symbolic Frame}

Ideas distilled from the world of social and cultural anthropology are the main drivers of the symbolic frame of organizations in general and educational organizations in particular. The symbolic frame views educational organizations as tribes (academic tribes) with cultures characterized by core values, norms, beliefs, traditions, rituals, among others. Consequently, what is more important in shaping the lives and actions of the various stakeholders are the rituals regularly enacted, ceremonies of what is valued, stories with important themes and myths recounted by members (Bolman and Deal, 1991). In other words, the lives and actions of stakeholders within the education sector are not only dominantly shaped by laid down rules and regulations, adopted policies and the formal authority of educational administrators. This partly explains the assertion by Fullan (1993) that the only thing of importance that leaders within educational organization can do is to create and nurture an enabling culture. Within the symbolic frame problems are either explained by the inability of the various participants to adequately perform assigned tasks, the loss of meaning of symbols, and reduced potency or power of ceremonies and rituals. The rituals, core values, symbols, myths, ceremonies, songs etc. constitute what has been referred to as the spiritual side of life within an organization (Schein, 1985; Bolman and Deal, 1991). In the event that things are not going on well (in this case, schools are unable to adequately respond to concerns about inadequate levels of inclusion), the symbolic frame will require that the symbolic elements (core values, norms, traditions, ceremonies etc.) be revisited in order to ensure that they align with the core values of educational organization. A key implication of the symbolic frame is that policies and practices of inclusion need to be grounded on core values or the spiritual side of educational organizations.

If attention is not paid to the symbolic dimension of organizations (for example, core values, rituals, and ceremonies) a critical element will be missing from inclusive education practices. For example, the prevailing culture of a school will significantly affect efforts aimed at greater inclusion. Policy makers and other stakeholders have a collective responsibility for creating and sustaining an enabling inclusive culture. An enabling culture is likely to have a transforming effect in all the members within an inclusive setting, creating needed synergy as stakeholders, characterized by great diversity, become members of an inclusive family with a shared purpose and spirit. Policy makers and leaders are expected to serve as priests, whose responsibility is to ensure the perpetuation of the spiritual or cultural dimension of the organization, ensuring that core values are not compromised. Using the symbolic frame, the inability to achieve higher levels of inclusion will be explained by the absence of enabling cultures within educational organizations. Teachers cannot make teaching exciting, interesting and challenging for children if they themselves do not find teaching interesting, exciting and challenging.

In addition to the literature on the unique characteristics of educational organizations, I have relied heavily on ideas by Harold Howe II (1993) in his book entitled Thinking About Our Kids: An Agenda for American Education. The overarching argument of Howe II is that those who seek to reform schools and make them more interesting and exciting places for all children need to first of all be reformed. In other words, we need to, as he puts it reform the reformers. Their thinking, he argues needs to be reformed because they pay too much attention on schools rather than to children. They are myopic in their conception of education, choosing to view it, for the most part, as what happens to children while they are in schools while neglecting circumstances of families and communities which are critical to teaching and learning for all children. These ideas which have been significantly borrowed from Harold Howe 11 constitute in my opinion the way forward to make inclusion a reality. Stated in point form they call for greater efforts to strengthen families and communities, recognize the difference between education and schooling, accept the reality that a competitive culture has the potential to hurt inclusion, avoid the fragmentation of services, treat students as human beings with unique characteristics and experiences that can inform the inclusion agenda, acknowledge the importance of money in efforts to make inclusion a reality, and re-think and revise how time is used in schools. Each of these themes is pursued in greater detail in the lines that follow.

\section{Strengthening Families}

We cannot afford to ignore the contributions of families and communities in our efforts to provide education to all. Our policies must address the role of parents and other sources of learning, and more particularly the media. For example, the audio-visual median is rapidly becoming the most common source of learning for most children as economic and 
other circumstances erode traditional links between families. Families and communities can either help or hurt inclusion efforts by what they do or fail to do. For example, the traditional African family is no longer what it used to be - a strong support base made up of extended family members. We are increasingly becoming more nuclear in our conception of the meaning of a family. This has eroded the support available to children at a time when economic and other imperatives are putting enormous strain on human relationships.

There are a lot of indicators that point to the fact that we often pay more attention to schools than to children. For example, greater emphasis on accountability (.e.g. measuring achievement and rewarding it; strengthening standards using different forms of assessment to gauge how well students and schools are doing, etc.) constitutes vivid testimony. Efficiency is a very common concept in educational organizations. It should, some would argue, because of scarcity of resources and the need to maximize returns on what is available. However, many educators are very suspicious about efficiency. Paying too much attention to accountability and value for money concerns (efficiency) can hurt the realization of the goals of inclusion.

There is no doubt that some students can defy poverty and other burdens and perform at high levels. In spite of this possibility, the chances are higher that most will not. The fact that some schools enable students to learn and achieve at higher levels is very good news. However, it should not be interpreted to mean that schools should be blamed for most students who perform poorly. On the other hand, other scholars are of the opinion that the origins of poverty and family disruption, need to be addressed to enable young people in schools receive the various forms of support they need to be successful. Policy makers and practitioners need to pursue both options rather than view things using an either-or logic.

Many policy proposals and ensuing actions to improve education are dominantly focused in the direction of schools. The policies and actions fail to realize that alone schools cannot improve learning for all students, particularly the traditionally neglected subgroups. Reform efforts must be based on systemic thinking because children have many lives that are interrelated (for example, lives spent in and out of schools). In terms of conversations on inclusive education this must constitute one of the main policy pillars. Such conversations must consider the contributions of families and communities. Not doing so will constitute naivety, deliberate neglect or ignoring what obtains in the real world. This point has been beautifully captured by Howe II (p. 29) when he asserts that:

It is either naïve or irresponsible to ignore the connection between children's performance in school and their experience with malnutrition, homelessness, lack of medical care, inadequate housing...discrimination, and other burdens.

Many children in Cameroon are growing up today without spending quality time with their parents and other adults whose support has the potential to enable them grow into mature and responsible adulthood. The contemporary Cameroonian society, especially in the urban areas is eroding what Howe 11 refers to as "the intergenerational exchanges on which maturity is successfully built" while asserting that "the schools, no matter how much we reform them, cannot make up for the support children are losing because of changes in families and communities."

Excessive TV watching television, poverty, and absence of parents have also been identified by the Educational Testing Service (ETS, 1992) in the United States of America (USA) as obstacles to learning. The same source also considers the availability of home libraries, reading at home, parental involvement in schools, and adequate family resources as having positive influences on learning for all children. In addition ETS also recognizes "the love and attention children receive, the security they feel, the encouragement they get to learn, and attention given to their health" as essential to learning within schools. Though the context of these views by the ETS is the USA, to a very large extent the same can be said of Cameroon today. What children watch on TV is hardly edited and other developments in information and communications technology are hurting the provision of quality education to all students. The problem is that the variables associated with learning (the love and attention received by children, and other forms of support) are not equally distributed within the population of Cameroon. As a consequence some children are advantaged over others. Policies need to be adopted and implemented in order to reduce disparities of home background variables associated with teaching and learning.

\section{Recognizing the Difference between Education and Schooling}

Many educational policies in general and those aimed at creating an enabling environment for inclusion are for the most part based on a wrong or myopic conception of education. They assume that education is what happens to children in schools. It is essential that policy makers make a clear distinction between education (learning that takes place everywhere) and schooling (that part of education that takes place in places we call schools). It is my strong conviction 
that all stakeholders are interested in ensuring that schools at all levels are more inclusive places. My worry lies with how we have traditionally approached the issue. We have, as Howe 11 (1993) has observed, tended to pay much more attention to schools than children and base educational policies and practices on the assumption that if schools are fixed, they will in turn fix children. The problem with this assumption or way of thinking is that it prevents us from conceptualizing education from a systemic policy/practice perspective. It focuses attention on schools rather than education. Some of the laws that are significantly shaping the education sector in the Republic of Cameroon are based on this myopic conception of education.

The recommendations of the 1995 National Education Forum in the Republic of Cameroon and those of the 2006 Technical Committee Charged with the Elaboration of a Sector-Wide Policy Document for the Education Sector (SWAP) are significantly influencing thinking and actions aimed at revitalizing the education sector in Cameroon. For example, Law 98/004 is partly based on the recommendations of the 1995 National Education Forum. Most education reform initiative in this country, albeit myopically, conceptualize education as what happens when students and teachers are together. For the most part they fail to recognize the roles of other stakeholders (for example, families, the media, communities, the church and other social institutions) in the educational process. Even though 98/004 makes mention of the concept of an educational community, much has not been done to actualize this concept as many policy makers and educators, let alone the common person in the street, continues to equate education with schooling. The danger is that this myopic conception rends to reinforce reform efforts that pay more attention to schools rather than being based on a holistic practice perspective.

The government, the private sector and other stakeholders need to be committed to a broader definition of education. Such a commitment will require that stakeholders, particularly policy makers, acknowledge factors that have been traditionally neglected in discussions about education, among them poverty, various forms of ethnic discrimination with the potential to affect children's experience with schools and their subsequent levels of achievement.

\section{A Culture Dominated by Testing and Examinations Hurts Inclusion}

One of the essential values shaping the lives of educators, students, and their families is that of competition. This is often indicated by the use of tests and examination to either gauge the success of students, teachers and schools. There are scholars (for example, Howe II) who are of the opinion that for the most part poor performance on tests and examinations often gets interpreted negatively and learners, teachers, and schools blamed when in actual fact they could be indicative of greater inclusion. Harold Howe II argues that poor academic performance is likely to be an observed outcome, albeit in the short run, when traditionally neglected groups are being included in educational experiences. For example, the inclusion of many more learners from traditionally neglected segments of the population such as the girl child, learners with various forms of disabilities and those from poor home backgrounds, is likely to pull standardized test and examination scores down. Consequently, poor academic performance as measured by traditional testing instruments could positively be interpreted to signal greater inclusion (what Howe 11 refers to as "a major gain in equality of educational opportunity) rather than vivid testimony of the failure of students, educators, and schools.

A major theme that runs in Howe 11's work and that should undergird education policy is that performance on an examination/test will be powerfully influenced by the personal circumstances of test takers or those who write examinations. This is because examinations do not only measure what is taught in schools but also the learning that takes place in other settings (e.g. home, the ability of students to engage in critical debates with their peers, enabling environments at home for homework to be done, among others).

Educational systems are likely to be less inclusive if they are pervaded by a very competitive philosophy which places greater emphasis on individual rather than group achievement. This is because students are often polarized into winners and losers. Competition is evidenced by such practices as excessive reliance on tests and examinations scores to compare students and schools. We need to encourage cooperative practices so that students do not see themselves as adversaries but as individuals capable of supporting each other in a win-win situation. Cooperation is likely to enable students see others as a source of learning and build healthy human relationships required for inclusion for sustainable development. When students are encouraged to work in teams, they bring their varied competencies and experiences to the teaching and learning situation and consequently make the learning process more exciting and inclusive.

\section{Avoiding the Fragmentation of Services}

The government is struggling to strengthen families and communities. However, the problem is that its efforts are 
fragmented among various ministries and agencies with little or no coordination. One of the required policy initiatives is to ensure that services aimed at improving schools (making them more inclusive, among other things) through strengthening families and communities require a new approach by the government. The Report of the Technical Committee charged with the responsibility of Elaborating a Sector-wide Approach to Education (2006) is a step in the right direction. Members were drawn from different education ministries and those with implications for education (for example, ministries of basic, secondary, higher education; ministries of labour and professional training, economy and finance, planning and regional development) and this nation's development partners.

The ministries are for the most part separated from each other in terms of their programmes. They may be dealing with the same families but through different funding streams with the potential to lead to significant duplication of effort and wastage. To the extent that their activities are related, they should be jointly planned and implemented or else they will operate as rivals vying for available funds provided by the government or friendly donor organizations. There is therefore need for more effective connection and coordination between the various ministries and agencies which serve the needs of families and children (Howe, II). The Republic of Cameroon has made progress (for example adopted enabling legislation) in responding to increasing calls for inclusion. While this is commendable, the problem is that it is not often accompanied by adequate funds for implementation. It is stated in many of the laws that implementation modalities will be addressed by subsequent legal instruments. One of the weaknesses of policies of inclusion is that attention is often not paid to the details of implementation, monitoring and evaluation to determine impact.

\section{Treating Students as Human Beings}

Many educational practices can be described as being based on the logic that students are inanimate objects. For example, teacher-dominated pedagogical practices, standardized policies and practices fall within the category of practices that are not humane. "Students Are People Too" is the title of a chapter in Harold Howe's book. While in school, many students are often treated in ways that make them feel excluded. Many come to see schools as places that are not humane, interesting and challenging. The consequence is that this weakens the bonding between students who feel alienated and force significant numbers to dropout.

From the perspectives of reforms, many have the potential to hurt rather than help inclusion (for example, reforms aimed at specifying what must be studied and duration, ensuring greater rigor and higher standards, tests and examinations, among others). Reforms aimed at greater inclusion will require helping students to grow up to responsible adulthood rather than making them to respect and fulfil criteria aimed at shaping them up. Schools are likely to be more humane and inclusive if not dominated by the factory model. Factories are in the business of shaping raw, inanimate materials into finished products required by the society.

Most practices in schools are based on the factory model with the attendant consequence that the uniqueness of children is often forgotten. Students are not homogeneous. Some need more time to grasp the content of instruction while others need to be exposed to different pedagogical methods in order to succeed. With greater diversity in the school going population, schools are being challenged to serve groups that are more varied. We cannot talk about greater inclusion while neglecting or ignoring changes in the student population. This will, among other things, require fundamental changes in the curriculum, testing practices, and efforts to raise standards. For example, greater reliance on tests and examination may inadvertently force many teachers to teach in ways that enable students perform better in them at the expense of deeper learning. Students are not raw material to be shaped into uniform specifications prescribed by adults but human beings "with hope, feelings, and ideas about themselves formed by experiences both within and outside of the school." (Howe 11, 1993 p. 118).

Schools are quite rigid institutions, from organizational and pedagogical perspectives. There have been efforts in the past to move away from the factory model in order to make schools more humane teaching and learning environments. Examples include the progressive education movement in the 1920s and 1930s as well as life adjustment education introduced after the Second World War. Life adjustment education was based on the logic that schools are likely to be more relevant and inclusive if based on content that is drawn from students' experiences. Another initiative aimed at making schools more inclusive was developed by James Comer (1970). His overarching aim was to ensure that schools were places within which the various stakeholders knew each other and treated them with respect. Members were also expected to make the school more friendly and stimulating. In other words all members were expected to feel a common bond. Within such an environment, tests and examinations are not repeatedly used to inform students that they are failures, but one within which they are often praised for their little accomplishments and parents are welcomed and respected as critical partners rather than intruders. Test and examination results are viewed as manure for teaching and 
learning. If excessively used, they will create and perpetuate teaching environments not open to mistakes and risks, both of them prerequisite for enabling teaching.

The main point being made is that some schools are not communities within which the various members treat each other with respect. Adult are supposed to respect young people and vice versa. With trust and respect from teachers, the bonding between young people and schools is likely to be stronger as many students start believing in their own ability to achieve at higher levels. They will be more willing to take risks that are part of the learning process and such willingness will require that adults develop and sustain high expectations for all students. Schools may not be inclusive because students do not like them, partly because they are regularly being bombarded by negative messages about their abilities.

Educational organizations have both positive and negative outcomes. From a negative perspective, educational organizations can lay the foundation for the exploitation of man by man. They can, in addition, be very frustrating places for those who work in them as well as learners. For example, some scholars within the sub discipline of sociology of education have argued that schools exist to perpetuate the social inequalities rather than ensuring equality of opportunity. Some schools have been described using metaphors as factories, graveyards, prisons (Howe II) instead of being interesting, exciting and challenging places. Rather than being in the business of critically opening up the minds of children by, among other things, encouraging and celebrating diversity in Cameroon, many schools are either knowingly or unknowingly closing their minds by discouraging the development of critical thinking skills.

\section{Revisiting How Time Is Used In schools}

Some of the pedagogical practices within schools have been compared to practices used by Procrustes. Procrustes was a legendary hazard to travellers as stated in Greek mythology. Procrustes had a bed to which he forced his victims to sleep on it. Each of them was supposed to nicely fit into the bed. Victims who were too long had their feet cut off while the short ones were stretched to fit the bed. From this Greek myth, the concept of the Procrustean bed was born. Many practices within schools resemble what Procrustes did to his victims. For example, the use of time for teaching and learning do not often acknowledge individual differences between students as all of them are supposed to meet the same requirements within the same allocated time. Students are all supposed to learn at the same speed and using the same instructional methods. Tests and examinations are given at the same time to all, regardless of their readiness.

To be more inclusive, policies and practices must respect the diversity that characterises the student population (for example, learning styles, personal background variables, variables within the community, among others). Schools are not very inclusive partly because they do not respect the diversity that characterizes the student population. For example, their learning styles, background variables, among others.

\section{Money Makes a Difference}

Those interested or claim to be interested in inclusion for the most part behave in ways that suggest that money does not make a difference in the process of adopting and implementing relevant policies. Our conversations about inclusion need to involve consideration about money needed to give all children a good quality education and where it should come from. I am not in any way, shape or form suggesting that money alone is the answer to higher levels of inclusion. It is not how much money has been allocated to support inclusion but how it is used. Not used well it is tantamount to throwing money at the problem and this will not help the cause. Money is critical because inclusion is tied to the quality of healthcare, nutrition, and other socio-economic variables. It is tied to the ability of families to provide needed support to children and interact with them in constructive relationships. In this country, there is excessive dependence on the government and this needs to change by the diversification of funding for education, especially in public schools. We need money to raise the living standards of the poor, the traditionally disadvantaged segments of society, notably the girl child and those with various disabilities.

The education sector always receives the highest budgetary allocation in this country annually. However, allocated amounts do not tell the whole story in terms of how the money is used. More than $80 \%$ of the budget of the various ministries of education (basic, secondary and tertiary) is usually swallowed up by personnel related expenses. This leaves very little to other basic material resource inputs. Greater inclusion will, among other things, require policies aimed at diversification of sources of funding sources. This can be done by requiring the private sector to play a more active role in supporting formal education and rewarding them by tax breaks. In other words, companies that support education need to be identified and their taxes reduced. Another strategy requires companies, through enabling legislation, to adopt 
schools, especially those in hard to reach and often difficult areas. Funding for education can also be diversified through policies aimed at greater cost sharing while adopting affirmative actions to support sub-groups which do not have the capacity to do so for fear of using education to perpetuate social inequalities.

\section{Conclusion}

The issue of inclusion has everything to do with education from a broader and deeper perspective. Not doing so will constitute lip service in conversations about inclusion. Conversations and reflections about inclusion must not neglect such conditions as poverty and its various manifestations (e.g. hunger, lack or inadequate health care provision etc.). Many laws have been enacted to inform the process of inclusion in Cameroon (for example, No. 2010/002 relating to the protection of persons with disabilities; No. 83/013 on the protection of disabled persons and No. 90/1516 to lay down modalities for its implication, among others). The themes examined above are not reflected in these laws. In addition, schools need to pay attention to diversity (ethnic, tribal, socio-economic, cultural etc.). The following constitute sample questions that need to be asked and answered to close the gap between reality of inclusion and policy pronouncements. Is there any recognition of the educational importance of community and families? Do policies and practices provide the groundwork for making schools more humane, challenging and exciting places for teachers, students and other stakeholders? Is there evidence of strategies to deal with greater diversity? Is there a strategy to educate Cameroonians about one another and provide the poor with better opportunities? Are policies encouraging greater competition than a stronger sense of community? If we do not address these and other relevant questions, we may inadvertently be creating a time bomb rather than working towards greater national unity and integration by addressing the educational needs of traditionally neglected groups?

Policy makers need a foundation for thinking about educational organizations. One of the main problems is that thinking about educational organizations has been dominated by single rather than multi-frame thinking. We need multiple frames to better understand educational organizations in order to adopt, implement, and sustain policies and practices that further the goal of inclusion. We should not be blocked in what Bolman and Deal $(1991 ;$ p.4) describe as "psychic prisons" or the inability to examine recurring in new ways. In other words, they cannot reframe. The ability of viewing old problems in new ways (reframing) is a liberating experience and may help the change process (inclusion is about change) by closing the gap between intentions and reality. We know that many good intentions often fall short of being realized in the real world of practice. In every educator's or policy maker's arsenal should be a diverse collection of tools (frames) of the best possible quality in order to deal with the changing landscape of educational organizations.

This paper has, besides shedding light on other frames that can be used to inform policies and practices of inclusion, identified often neglected considerations culled from the work of Harold Howe II (1993) in efforts aimed at ensuring equality of educational opportunity. These among others include, de-emphasizing the use of tests and examinations to judge the effectiveness of schools and the academic achievement of students, paying attention to personal background variables of students, strengthening families and communities, and marching rhetoric about inclusion with money and other resources.

\section{References}

Armstrong, E., Armstrong, A.c., \& Spandagou, I. (2011). Inclusion by choice or by chance? International Journal of Inclusive Education, $15(1), 29-39$.

Bolman, L.G \& Deal, T.E. (1991). Reframing organizations: Artistry, choice, and leadership. San Francisco: Jossey Bass.

Cameroon (1993). Law No. 83/013 of 21 July 1983 on the protection of disabled persons. Yaounde: Presidency of the Republic.

Cameroon (1986). Circular No. 86/1/658/MINEDUC/CT2 of 13 January 1986 relating to the protection of persons with disabilities. Yaounde: Ministry of National Education.

Cameroon (1990). Decree No. 90/1516 of 26 November 1990 to lay down the condition for the implementation of Law No. 83/013 of 21 July 1983 on the protection of disabled persons. Yaounde: Presidency of the Republic..

Cameroon (1995). National Forum on Education: Final Report. Yaounde: Ministry of National Education.

Cameroon (1996). Constitution of the Republic of Cameroon. Yaounde: National Printing Press.

Cameroon (1998). Law No. 98/004 of April 1998 to lay down guidelines for basic, secondary, and teacher education. Yaounde: Presidency of the Republic..

Cameroon (2006). Report of the Sector-wide Approach to Education. Yaounde: National Printing Press.

Cameroon (2010). Law No. 2010/002 of April 2010 relating to the protection and welfare of persons with disabilities. Yaounde: Presidency of the Republic.

Coleman, J.S., Campbell, E.Q., Hobson, C.J., McPartland, J., Mood, A.M., Weinfield, F. D., \& York, R.L. (1966). Equality of educational 
opportunity. Washington, D.C.: Government Printing Press.

Educational Testing Service (1992). America's Smallest School: The Family. Princeton, New Jersey: Policy Information Center.

Fuchs, L.S., \& Fuch, L. (1994). Inclusive schools movement and the radicalization of special education reform. Exceptional Children, 60 (4), 294-309.

Fullan, M.G. (1993). Visions that Blind. In Educational Leadership: restructuring schools (Ronald S. Brandt, editor). Virginia, USA: Association for Supervision and Curriculum Development.

Graham, L.J., \& Slee, R. (2008). An illusory inferiority: interrogating the discourse of inclusion. Educational Philosophy and Theory, 40 (2), 247-260.

Howe II, H. (1993). Thinking about our kids: An agenda for American education. New York: The Free Press.

Harold 11, H. (1991). "Let's Have Another SAT Score Decline," Phi Delta Kappan, November 1991, pp. 192-203

Patterson, J. L. et al., (1986). Productive school systems for a nonrational world. Alexandria: Association for Supervision and Curriculum Development.

Schein, E. (1985). Organizational Cultures and Leadership: A Dynamic View. San Francisco: Jossey-Bass.

Titanji, P.F. (2013). 50 years of education reforms in Cameroon. In David Abouem a Tchoyi \& Stephane Claude M'bafou (eds.). 50 ans de Reforme de l'Etat au Cameroon: Strategies, blans et perspectives (113-140). Yaounde: L'harmattan. 
